\title{
SÍNTESE DE DERIVADOS TRIAZÓLICOS DO ÁCIDO CAFEÍCO
}

\section{Brenda Zélia Rodrigues Ramos ${ }^{1}$ Hiago Martins Batista ${ }^{2}$ \\ Heberth de Paula ${ }^{3}$ \\ Renata Dalmaschio Daltoé ${ }^{4}$ \\ Pedro Alves Bezerra Morais ${ }^{5}$}

Resumo: O ácido cafeíco demonstrou interessante atividade antiproliferativa contra linhagens de células cancerígenas testadas, sobretudo para células do colo do útero. Sharpless definiu "Click Chemistry" como uma abordagem de ampla aplicação para ser utilizada na preparação de uma série de substâncias com grande diversidade química. Os triázois são compostos heterocíclicos que possuem 3 átomos de nitrogênio em um mesmo núcleo cíclico, de origem exclusivamente sintética, não ocorrendo na natureza. Esta classe de compostos vem despertando interesse pela ampla aplicação, inclusive em relação à atividade antitumoral. Neste trabalho está descrita a preparação de novos derivados triazólicos do ácido cafeíco, via cicloadição 1,3-dipolar de Huisgen, através da conjugação entre o ácido cafeíco e azidas funcionalizadas, e a caracterização das moléculas formadas a partir da análise RMN de ${ }^{1} \mathrm{H}$.

Palavras-chave: Ácido Cafeíco, Produto Natural, Triazóis, Síntese Orgânica, Química Medicinal.

\footnotetext{
${ }^{1}$ Farmácia/UFES, Brasil. Email: brendarramos@hotmail.com.

2 Farmácia/UFES, Brasil. Email: hiago_mbatista@hotmail.com.

3 Departamento de Farmácia e Nutrição-CCENS/UFES, Brasil. Email: hdepaula@gmail.com.

4 Departamento de Ciências Farmácêuticas-CCS/UFES, Brasil. Email: redaltoe@yahoo.com.br.

${ }^{5}$ Departamento de Química e Física-CCENS/UFES, Brasil. Email: pedmora2005@gmail.com.
} 